\title{
Representation Matters but is Not Enough
}

\author{
Susan Hadley ${ }^{1}$ * \\ Editor \\ 1 Slippery Rock University, USA \\ *susan.hadley@sru.edu
}

Published: 1 July 2021

It is difficult to believe that it was just twelve months ago that I wrote an editorial for Voices entitled, "Change." In that editorial, I discussed multiple changes that were occurring in the world due to COVID-19 (at the time not realizing the extent to which lives throughout the world would be impacted by the pandemic), global protests demonstrating against anti-Black racism, and some major changes in personnel at Voices, including the departure of its co-founder Brynjulf Stige and one of its co-editorsin-chief Kat McFerran. Here we are 12 months later, and in many ways it is as if we are stuck in time. The pandemic continues to rage around the world, disproportionately affecting Black, Indigenous, and Brown communities. With the production of vaccines, many people are beginning to venture out with perhaps less anxiety than a year ago, although, again, how this is playing out around the world is that there is unequal access to vaccines and adequate medical care across and within countries, based on racial and wealth inequities. Racial unrest continues to be experienced globally, with increased protests demonstrating against anti-Asian racism as well as anti-Black racism. Relatedly, protests demonstrating against human rights violations are occurring as I write this, such as in response to the treatment of citizens and activists in Colombia, Myanmar, Palestine, Hong Kong, Ethiopia (Tigray), Uganda, Belarus, and Russia. Additionally, there are global protests about climate change and other environmental concerns, which threaten our very existence on the planet. Moreover, I must note that I am writing this during Pride in the US, as the human rights of LGBTQI + folk continue to be threatened, again disproportionately based on intersectionality.

Over the past twelve months, changes have continued to occur at Voices. Two more of our article editors have decided to leave their positions for a variety of reasons. It is with much appreciation for their dedicated service and with sadness that we say farewell to Marisol Norris and Melody Schwantes in their roles as editors. Each brought unique aspects to the Voices team and we will miss having their distinctive and irreplaceable perspectives on the team. Other article editors are also stepping back from their duties temporarily due to personal circumstances. As such, we have recently added several new article editors to our team. These are (in alphabetical order) Nicky Haire, Ming Yuan Low, Danielle McKinnon, and Carolyn Shaw. These new members combined with our continuing team of editors represent a diverse group of music therapists in terms of race, language, gender, sexuality, disability, ethnicity, religion/ spirituality, age, years in the profession, and geographical region. As we continue to expand our team at Voices with a commitment to increasing our diversity, we under- 
stand well that while representation matters, it is not enough. It would be easy for us to celebrate how we are committed to social equity and justice, citing that we are an open access journal, that we translate abstracts into multiple languages, have special issues devoted to significant social issues, and have an editorial board made up of a diverse group of music therapists. However, we must ensure that we go beyond inclusion of voices and perspectives, and work hard to interrogate the ways in which we continue to uphold dominant ideologies in music therapy. We need to address our ways of doing things, how we mentor, who we mentor, what we communicate, how we communicate, about whom we communicate, etc. We cannot rest in an attitude that we are doing more than others. We need to investigate the most difficult spaces to consider.

As a white nondisabled English-speaking cis-woman academic in music therapy, I continue to uphold hegemonic structures in many ways often without realizing it. On several occasions, I have been unaware of the ways I am contributing to oppressive structures by claiming there is nothing I can do to change the ways we operate at Voices. At these times, my awareness has come at the emotional labor of Black cis-women, disabled cis-women, non-binary folk, and non-English speaking music therapists. While many times I do feel powerless to make changes, it is important to continue to interrogate ways in which feelings of helplessness mask complicity with hegemonic structures that do not affect me in the ways that they affect minoritized people within our communities. I, for one, have been sitting in this discomfort this year and am committed to work to unveil the ways in which we as a community at Voices must work even more diligently in the quest for equity for all.

I am excited to share that we have a diverse array of articles in this current issue of Voices. Several address significant sociopolitical themes. Juanita Eslava Mejía provides a commentary about the current protests and social and political unrest in Colombia, as well as the role of music within this movement and Colombian music therapists' responses to it. She also provides a wonderful resource of protest music that she has compiled.

Due to ongoing political unrest in Palestine, Syria, Iraq, Afghanistan, and Eritrea, citizens from these countries have fled as refugees and asylum seekers to other countries. Two of the articles in this issue address work with people in these circumstances. Deborah Parker, Dario Gentili, Henry Brown, and Alberto Balducci describe the development of "Music and Resilience," a project that aims to build music resources with, and for, Palestinian refugees in Lebanon. This project involves international cooperation between a Palestinian non-governmental organization in Lebanon and an Italian community-based organization, and began in response to the Italian Embassy of Beirut's refusal of entry visas into Italy for fifteen young Palestinian musicians invited to participate in a cultural exchange in 2011 . The program focuses on community music-making and clinical music therapy with children and adolescents. Relatedly, Tina Mallon and Monika Hoog Antink share their COntext-sensitive classification model for music therapeutic interVEntions with Refugees in insecure circumstances, which they refer to as COVER. They describe this trauma-informed work with refugees and asylum seekers in Germany who fled from Syria, Iraq, Afghanistan, and Eritrea. Through music therapy, they provide support in the earliest stages of the process when people first arrive in the reception centers, to the follow-on camps, and then later in longer-term individual therapy.

Also focused on people who have experienced trauma are two articles, one by Lora Heller and an interview by Wei Wah Angela Shum. Lora Heller describes her international service trip to Jamaica to provide music therapy as part of mental health services for residents of a "safehouse" for adolescent girls who have experienced neglect or abuse, victimization, and sexual assault, or those in conflict with the law. The program's aims were "to provide an outlet for self-expression, an opportunity to foster resilience, a strengthened sense of community, and a supportive response to trauma." In Shum's interview with Dag Körlin, they discuss his model of Music Breathing to modulate arousal evoked by music listening in a non-ordinary state of consciousness for people who have experienced trauma. Music Breathing combines breathing with music 
listening as a safe approach for clients for whom Guided Imagery and Music or Music Imagery may be overwhelming and beyond their window of tolerance. This interview provides a conversational space in which Körlin reflects on his practice of music breathing.

Also reflecting on her practice is an article by Susannah Wettone, who delineates the ways in which the expectations of a person referring someone for music therapy influences the client's expectations, which, in turn, can affect the therapy process. When working privately, referrals do not just come from informed health professionals, but can come from people in the community, or even family members. She stresses that communication between the referrer and the therapist and mutual understandings of how music therapy can meet the client's needs are crucial parts of the process.

Relatedly, two articles in this issue are reflections on the current state of practice not of one music therapist, but a large group of music therapists working in a particular area of practice. Katrina Skewes McFerran, Giulia Fedrigo, and Andreas Wölfl conducted an international survey to gain information about the current state of practice and training of music therapists work with adolescents. They made their survey available in three languages and had responses from music therapists from 25 countries. One of many things they learned was that throughout the world, emotional and relational goals are the most frequently addressed with this age group.

Also utilizing information from an international survey, Kirsi Tuomi, Grace Thompson, Tali Gottfried, and Esa Ala-Ruona set out to learn more about the professional perspectives and approaches of music therapists who work with families around the world. They learned that while in recent years more and more music therapists are working with families, there is little specific training for music therapy trainees in family centered theories. Similar to the survey on work with adolescents, their research also showed that music therapists work to address emotional and relational goals with families, as well as empowerment and support.

Two other research studies in this issue focus on work with people living with dementia. Lisa Kelly and Bill Ahessy, committed to sustaining the personhood and sense of identity of people living with dementia, conducted a study that sought to learn more about the effects of reminiscence-focused music therapy. Their study demonstrated "that the focused combination of both music therapy and reminiscence with associative items is an effective way of promoting positive mood and engagement levels, shared interaction and reminiscence for people with dementia." Focusing not on the effect of the music on the client, but on the music therapist's experience, Nicky Haire and Raymond MacDonald's arts-based research centers music improvisation as a means for self- and collaborative reflexivity on the experience of humour by music therapists within their work. Their analysis offers "insight into how music therapists conceive of humour in their work as supportive of relational bonding, and also experience humour as distancing and defensive behaviour."

Two of the articles in this issue bring unique perspectives on how we understand music in our work. Kjetil Høyer Jonassen discusses music technology in music therapy, focusing on the human-computer interaction and the co-creation of mental health. Drawing on actor-network theory, agency, and affordance-theory, he suggests that the iPad should be considered a valuable co-agent in promoting adolescents' mental health. Aaron Moorehouse, a composer of experimental music, provides a commentary in which he suggests that the decentering of conventional music, and even sound itself, in contemporary music practices has implications for music therapy. His commentary left me pondering many questions - What is music? Are we imposing a sonic form onto clients, and is this always in the interest of the client? Are we delimiting and prescribing the nature of music?

Finally, two of the articles in this issue provide synopses of important book resources for music therapists, both centered on singing or song writing. One is a review by Lillian Eyre of Kelly Meashey's book The Use of Voice in Music Therapy. The other is a description by the author, Gabrielle Banzon, of her process of developing Space: A Journal for (Future) Music Therapists to Explore and Express Through Songwriting, a re- 
source for music therapists that helps music therapy students and music therapy professionals develop skills needed for effective song writing.

As we continue to evolve at Voices and continue to amplify its mission, we invite you to join in critically engaged dialogue in an effort to unmask the ways that we continue to uphold hegemonic practices that are exclusionary of a multiplicity of perspectives dedicated to the eradication of social injustices. 